\title{
Autosomal Dominant Microcephaly With Normal Intelligence, Short Palpebral Fissures, and Digital Anomalies
}

\author{
Jeffrey W. Innis, ${ }^{1,2 *}$ James H. Asher, Jr., ${ }^{4}$ Andrew K. Poznanski, ${ }^{5}$ and Susan Sheldon ${ }^{3}$ \\ ${ }^{1}$ Department of Pediatrics, University of Michigan, Ann Arbor \\ ${ }^{2}$ Department of Human Genetics, University of Michigan, Ann Arbor \\ ${ }^{3}$ Department of Pathology, University of Michigan, Ann Arbor \\ ${ }^{4}$ Department of Zoology, Michigan State University, East Lansing \\ ${ }^{5}$ Children's Memorial Hospital, Chicago, Illinois
}

\begin{abstract}
We describe a family segregating an autosomal dominant mutation producing a syndrome comprising microcephaly with normal intelligence and short palpebral fissures together with variable signs including thumb hypoplasia, shortness of the middle phalanges of the second and fifth fingers, small feet, a gap between the first and second toes, and mild syndactyly of the toes or fingers. A characteristic radiologic finding in our family is thinning of the proximal end of the first metacarpal and shortening of that metacarpal. The severity of these findings was asymmetric in our patients. This syndrome is similar to patients described by Brunner and Winter [1991: J Med Genet 28: 389-394], Feingold [1975: Synd Ident 3:16-17, 1978: Hosp Prac 13:44-49], and König et al. [1990: Dysmorphol Clin Genet 4:83-86]. Am. J. Med. Genet. 71:150-155, 1997.

○ 1997 Wiley-Liss, Inc.
\end{abstract}

KEY WORDS: microcephaly; autosomal dominant; digital anomalies; thumb hypoplasia; short palpebral fissures; syndactyly

\section{INTRODUCTION}

We describe a family with apparent autosomal dominant transmission of microcephaly and digital anomalies. Affected individuals consistently have microceph-

\footnotetext{
Contract grant sponsor: University of Michigan Multipurpose Arthritis and Musculoskeletal Diseases Center; Contract grant sponsor: Scott Collins Memorial Fund.

*Correspondence to: Dr. Jeffrey W. Innis, Department of Human Genetics M4708 Medical Science II, Ann Arbor, MI 481090618.
}

Received 13 May 1996; Accepted 27 January 1997 aly $(\mathrm{OFC}<3$ rd centile) and short palpebral fissures; however, there is considerable variability and individual asymmetry in the defects of the limbs. The major limb anomalies are hypoplastic, slender thumbs with limited flexion at the distal interphalangeal joints of thumbs and some fingers, thin proximal first metacarpals, and short middle phalanges of the index and fifth fingers. We present radiographs and a metacarpophalangeal profile analysis to facilitate the identification of other patients with this syndrome.

\section{CLINICAL REPORT}

The pedigree is shown in Figure 1. Table I summarizes the abnormalities identified in affected family members [Hall et al. 1989].

The propositus, individual III-3 (Fig. 2B), was born at 38 weeks of gestation to a 30 -year-old $\mathrm{G}_{7} \mathrm{P}_{2}$ white woman by spontaneous vaginal delivery after artificial rupture of membranes. Alcohol, tobacco, and drug abuse were denied. The pregnancy was uncomplicated. Apgar scores were 9 at one minute and 9 at 5 minutes. At birth, the child weighed 3,640 g (70th centile), length was $52 \mathrm{~cm}$ (55th centile), and the head circumference (OFC) was $32 \mathrm{~cm}$ (5th centile). She smiled at 2 months and began babbling at 3 months. At 3 months OFC was $36 \mathrm{~cm}$ (<3rd centile or approximately 50th centile for an 11-week-old infant). Her head appeared microcephalic with biparietal narrowing. The anterior fontanel was open and there was a prominent lambdoid ridge. Skull films showed open cranial sutures. The inner canthal distance was $2 \mathrm{~cm}$, between the $3 \mathrm{rd}$ and 25th centiles for age. Outer canthal distance was 5.2 $\mathrm{cm}$, between the 3rd and 25 th centiles. The ears were 4.5 and $4.6 \mathrm{~cm}$ long (between the 75th and 97th centile) and were normal in shape and position. There were no preauricular pits or tags. She had a broad nasal bridge with normal shape and position to the nose. The palate showed no evidence of clefting. The neck was short. Clavicles were completely formed bilaterally. Cardiovascular exam showed a regular rate and rhythm with no murmurs. Extremity anomalies are listed in Table I. 


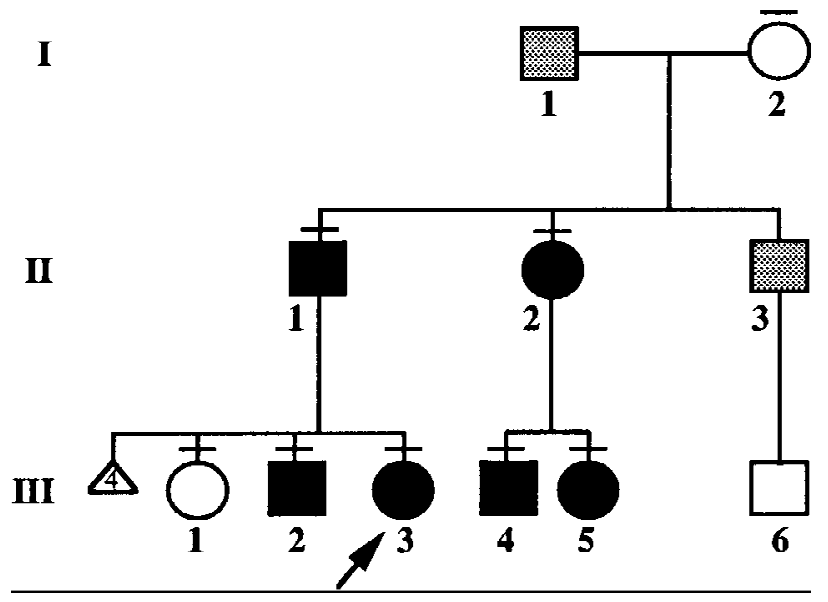

Fig. 1. Pedigree. Horizontal lines above pedigree symbols indicate those individuals examined by the authors. Four miscarriages occurred in generation three. Black filled in symbols are affected relatives; shaded symbols represent members who were not examined but are presumed to be affected based on information provided by the family.

There was no nail dysplasia. There was normal mobility of more proximal upper or lower limb joints. The right thumb showed the greatest restriction of movement. At 7 months the right and left total hand lengths were $8 \mathrm{~cm}(25 \mathrm{th}-50$ th centile). The middle finger length was $3.4 \mathrm{~cm}$ on the right and $3.3 \mathrm{~cm}$ on the left (25th-50th centile). Radiographic examination of the arms and legs showed normal osseous structures with no evidence of radioulnar synostosis. Both femoral ossification centers were present and symmetric. In the feet, the middle and distal phalanges of all toes appeared short. There was no evidence of ossification of the carpal bones at age 3 months, which suggested a minimal delay in bone maturation (Fig. 3B). There is thinning of the proximal end of the first metacarpal and shortening of the 2nd and 5th middle phalanges. Skull films at 7 months showed open cranial sutures.

Her brother, III-2 (Fig. 2C,E), was 4 and 2/12 years old at examination and was born at 39 weeks by spontaneous vaginal delivery. His Apgar scores were 7 at 1 minute and 8 at 5 minutes. The pregnancy was uncomplicated. Birth weight was $2,300 \mathrm{~g}$ ( $<3$ rd centile) and length was $49 \mathrm{~cm}$ (25th centile). He walked unassisted at 11 months. His teeth began to erupt at 9 months. It was not until $21 / 2$ years of age before his first words were noted and improvement was observed after speech therapy for 5 to 6 months.

On physical examination, height was $98.1 \mathrm{~cm}(10 \mathrm{th}$ centile), arm span was $97 \mathrm{~cm}$, weight was $16.0 \mathrm{~kg}$ (25th-50th centile), and OFC was $46.3 \mathrm{~cm}(<3 \mathrm{rd}$ centile or approximately 50th centile for a 10-month-old boy). The child appeared microcephalic with prominent lambdoid ridges and a low anterior hair line (Fig. 2C). The anterior and posterior fontanels were closed and there were no scalp or cranial lesions. The inner canthal distance was $2.7 \mathrm{~cm}$ (50th centile). The interpupillary distance was $4.3 \mathrm{~cm}$, which is between the 3rd and 25 th centiles. The outer canthal distance was $6.4 \mathrm{~cm}(<$ 3rd centile). Ear shape, size, and position were normal. There were no preauricular pits or tags. The child had a normal palate and normal teeth. He had a normal penis with descended testes, but slightly hypoplastic scrotum. There were no sacral dimples or pits. The back was normally curved. Thumb movement was restricted in flexion bilaterally particularly at the distal interphalangeal joints. The right and left hand lengths

TABLE I. Affected Family Member Anomalies

\begin{tabular}{|c|c|c|c|c|c|c|}
\hline & III-3 & III-2 & II-1 & $\mathrm{II}-2^{\mathrm{a}}$ & III- $4^{\mathrm{a}}$ & III- $5^{\mathrm{a}}$ \\
\hline $\mathrm{OFC}<3$ rd centile & + & + & + & + & + & + \\
\hline \multicolumn{7}{|l|}{ Palpebral fissure lengths $<3$ rd } \\
\hline centile & + & + & + & + & + & + \\
\hline Epicanthal folds & + & + & & & & \\
\hline Mild synophrys & & + & + & & & \\
\hline Hypoplastic thumb(s) & + & + & + & & & + \\
\hline Hypoplastic thenar musculature & + & + & + & & & + \\
\hline \multicolumn{7}{|l|}{ Short first metacarpals/thin } \\
\hline proximal first metacarpal & + & + & + & & & \\
\hline Short second and fifth fingers & + & + & + & & & + \\
\hline \multicolumn{7}{|l|}{ Inflexible DIP joints } \\
\hline thumbs or fingers & + & + & + & & & + \\
\hline Single palmar crease & + & + & & & & \\
\hline Mild syndactyly fingers $3 / 4$ & & & & + & & + \\
\hline \multicolumn{7}{|l|}{ Clinodactyly fingers 2,4} \\
\hline and/or 5 & + & + & + & + & & + \\
\hline \multicolumn{7}{|l|}{ Short middle phalanx } \\
\hline second finger & + & & & & & \\
\hline \multicolumn{7}{|l|}{ Single crease fifth finger/short } \\
\hline fifth middle phalanx & + & + & + & + & & + \\
\hline Foot length $<3$ rd centile & + & + & & & & \\
\hline Pes planus & & & & & & + \\
\hline Relatively broad great toes & + & + & + & + & & \\
\hline Gap between 1st/2nd toes & + & & + & & & \\
\hline Mild syndactyly toes $4 / 5$ & + & & & & & \\
\hline Mild syndactyly toes $2 / 3$ & & & & & & + \\
\hline
\end{tabular}

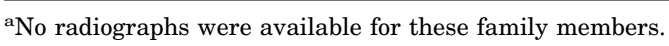



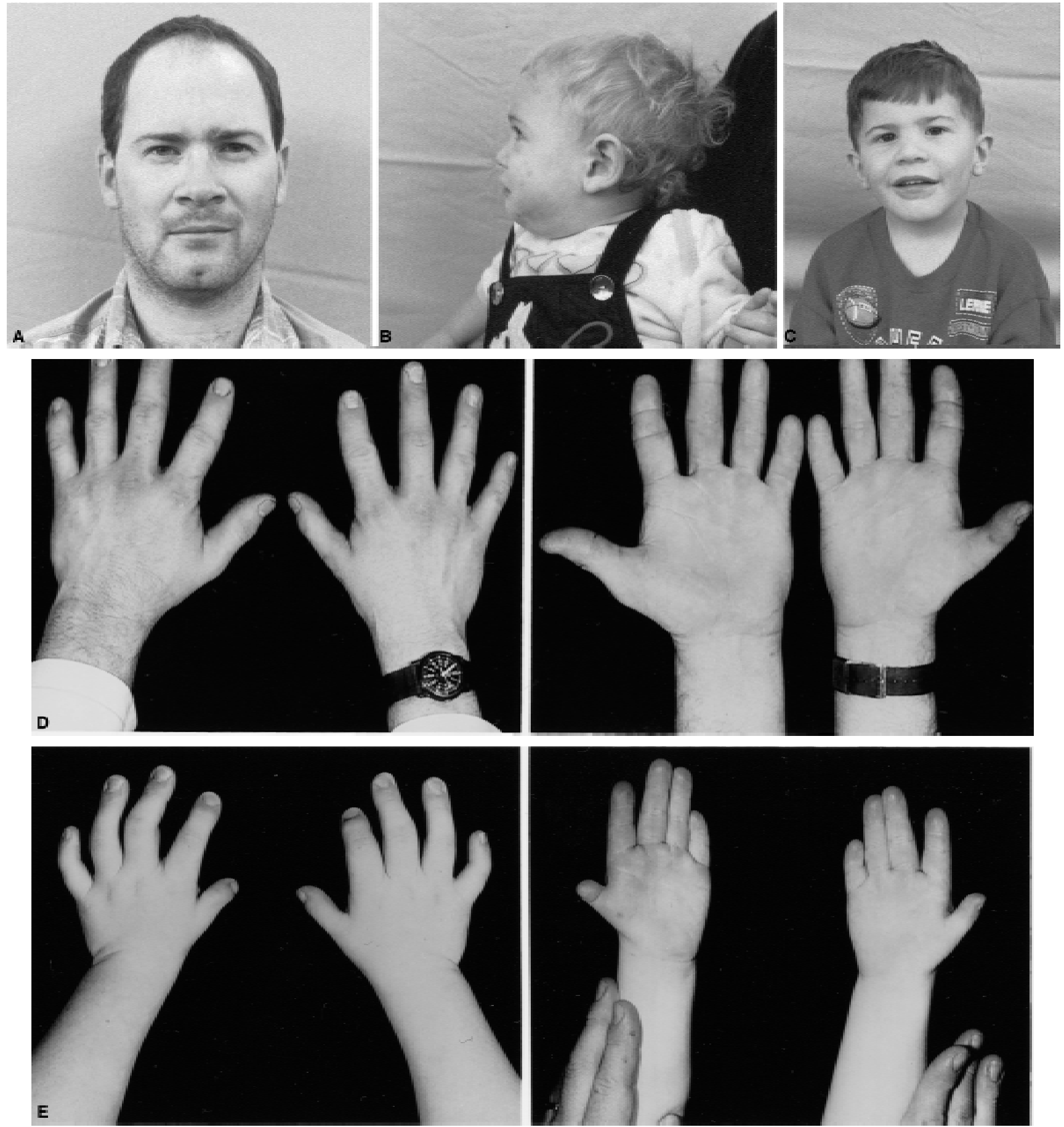

Fig. 2. Photographs of some affected individuals. See text for description. A: II-1, age 30 years, frontal view. B: III-3, age 7 months. C: III-2, age 4 and $2 / 12$ years, frontal view. D: Hand photographs of II-1. E: Hand photographs of III-2.

were 11.6 and $11.3 \mathrm{~cm}$, respectively (3rd-25th centile). The right and left middle finger lengths were 4.9 and $5.1 \mathrm{~cm}$, respectively, which is approximately the 50 th centile. There was no nail dysplasia. There was no restriction of movement or osseous abnormality of more proximal joints of the limbs. Radiographic examination of the hands revealed asymmetric thinning of the proximal portion of the first metacarpal, and marked shortening of the 2 nd and 5 th middle phalanges (Fig.
3C). Skeletal survey at birth showed open cranial sutures.

Individual III-1 had normal developmental history, growth, and physical findings. Her OFC was $42.5 \mathrm{~cm}$ (90th centile) at age 4-1/4 months. At 6-1/2 years head circumference was $53 \mathrm{~cm}$ (97th centile). Her palpebral fissure lengths were $2.4 \mathrm{~cm}$ bilaterally ( $<5$ th centile). No abnormality of her hands or feet was identified. Individual II-1 (Fig. 2A,D), the father of the children 

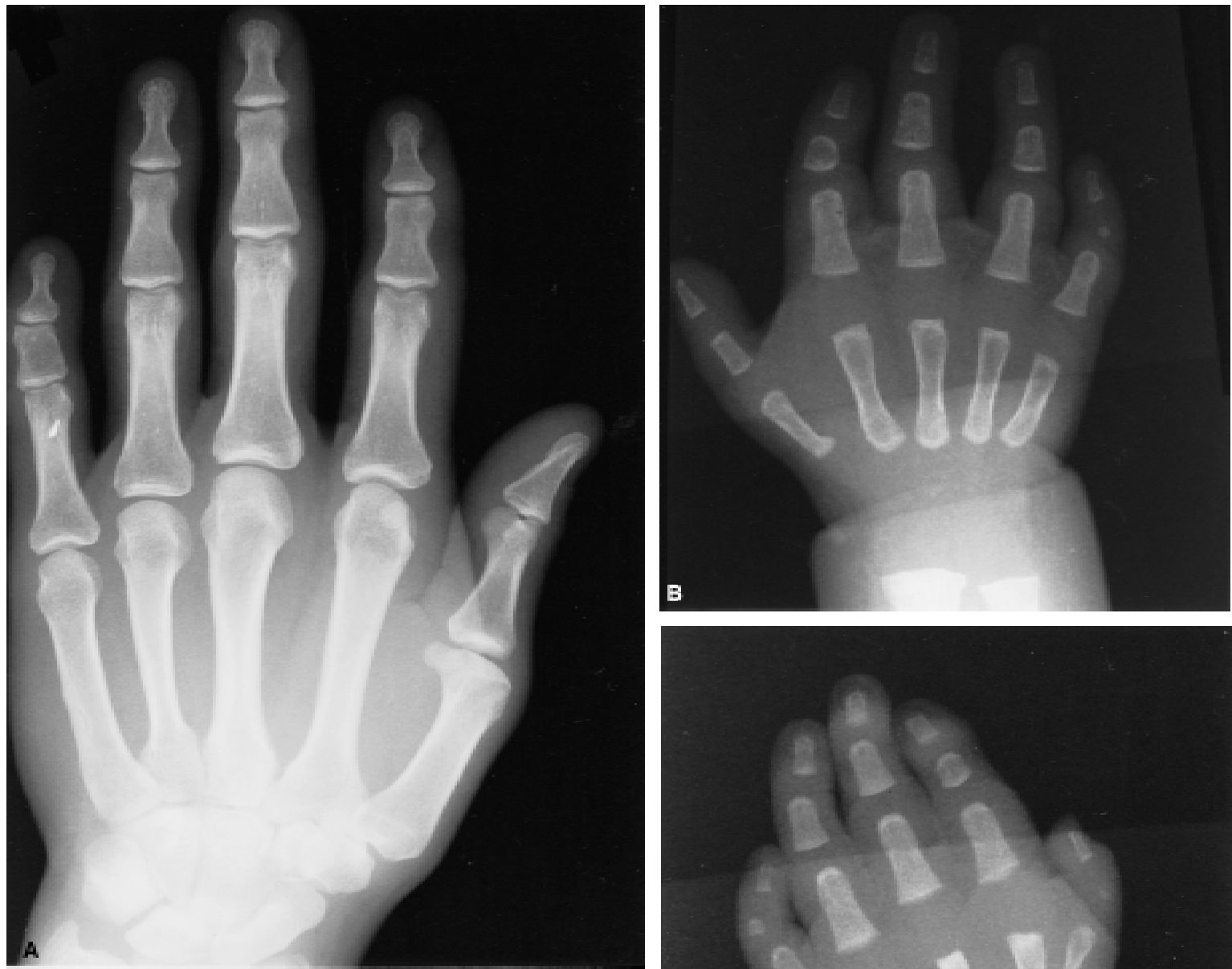

Fig. 3. Radiographs of hands of individuals in Figure 2. A: Left hand for II-1, age 30 years. The first metacarpal is short with flattening of its distal end. On the opposite hand there is thinning of the proximal end of the first metacarpal. There is some shortening of the 2nd and 5th middle phalanges. B: Right hand for III-3, age 3 months. There is shortening of the 1st metacarpal and thinning of its proximal portion. There is extreme shortening of the 5th middle phalanx and moderate shortening of the 2 nd middle phalanx. There is no carpal ossification. (The 50th centile for onset of the capitate is 0.25 years and the 95th centile is 0.6 years). C: Left hand for III-2, age 1 day. There is shortening of the 1st metacarpal and marked thinning of its proximal portion. The opposite 1st metacarpal was less affected. There is marked shortening of the 5th and 2nd middle phalanges. There is considerable hypoplasia of the first proximal phalanx. No radiographs were obtained for II-2, III-4, or III-5.

described above, was 30 years old at the time of examination. He had normal development as a child. He finished 12th grade as an average student and is currently a printing press assistant. Height was $174.8 \mathrm{~cm}$ (25th-50th centile), span was $174.5 \mathrm{~cm}$, weight was $85.4 \mathrm{~kg}$ ( $>97^{\text {th }}$ centile), and OFC was $52.2 \mathrm{~cm}(<3 \mathrm{rd}$ centile). His inner canthal distance was $3.1 \mathrm{~cm}$ (50th75 th centile). The interpupillary distance was $5.7 \mathrm{~cm}$ (50th centile) and palpebral fissure lengths were $2.4 \mathrm{~cm}$ ( $\ll 3$ rd centile). Ear lengths were normal. The nasal septum was deviated slightly to the left. Teeth were

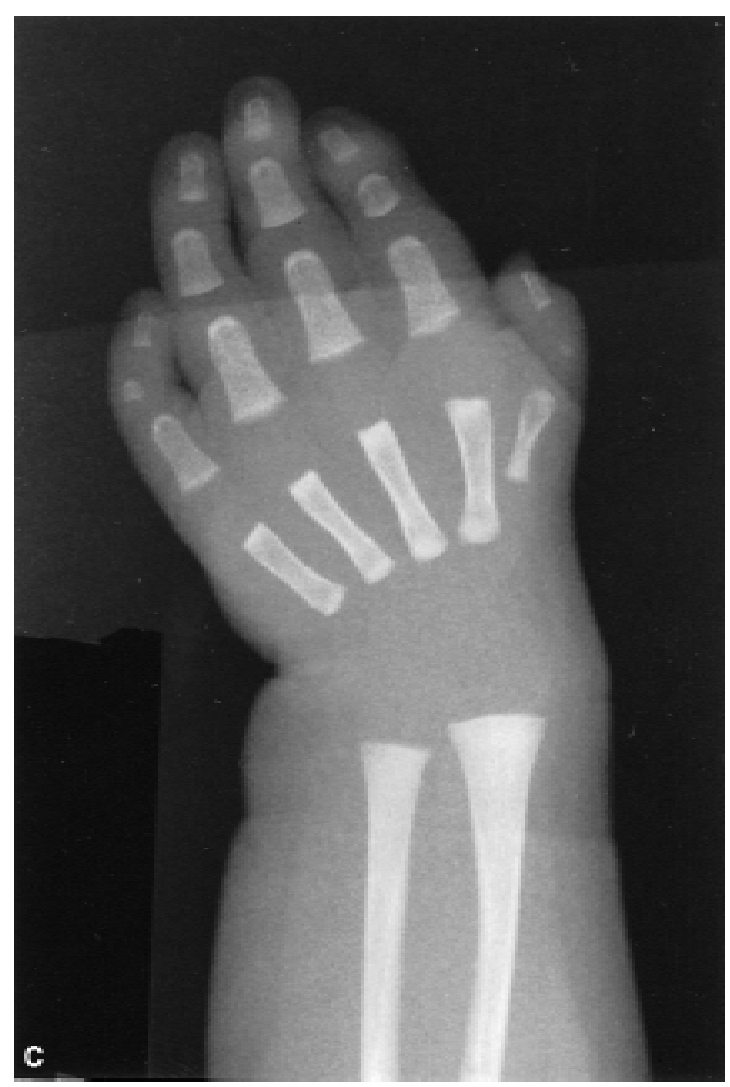

normal. Hand and middle finger lengths were normal bilaterally. He was left handed and the left thumb was larger than the right. He had hypoplastic right thenar muscles. The right thumb could not be flexed at the distal interphalangeal joint. The left thumb had normal creases and was flexible at the distal interphalangeal joint. There was no nail dysplasia. He had a slightly asymmetric chest with the right side being larger than the left. His back was normally curved. Chromosomes were normal (46, XY) without anomaly of 13q. Radiographic examination of the hand (Fig. 3A) 
is shown. There is shortening of the first metacarpal and flattening of its distal end.

Individual II-2 graduated from high school as an average student and took a business course for 9 months after graduation. She received speech therapy as a child. Her OFC at age 28 was $49.5 \mathrm{~cm}$ (<3rd centile) and height was $163 \mathrm{~cm}$ (50th centile). The inner canthal distance was $2.8 \mathrm{~cm}$ (25th centile), outer canthal distance was $7.5 \mathrm{~cm}(<3 \mathrm{rd}$ centile), and the interpupillary distance was $5 \mathrm{~cm}$ (3rd centile). There was no clinical thumb hypoplasia. Feet measured $23 \mathrm{~cm}$ bilaterally (25th centile).

Individual III-4 walked at 12 months, spoke words at 18 months, and talked in sentences at 3 years. He was $4-10 / 12$ years at the time of exam. OFC was $45 \mathrm{~cm}$ (<3rd centile) and height was $107 \mathrm{~cm}$ (50th centile). Palpebral fissures were $2.0 \mathrm{~cm}$ (much less than $3 \mathrm{rd}$ centile). Total hand lengths were at the 25 th centile. He had normal hands and feet.

Individual III-5 was 8-1/2 years old at the time of examination. She had a normal developmental history and is doing well in school. OFC was $46.25 \mathrm{~cm}(<3 \mathrm{rd}$ centile) and height $129 \mathrm{~cm}$ (50th centile). Palpebral fissure lengths were 2.1 and $2.2 \mathrm{~cm}$ ( $\ll 3$ rd centile).

Individual I-2 had an OFC of $54.75 \mathrm{~cm}$ (50th centile) and normal hands and feet.

Individuals I-1 and II-3 could not be examined; information derived from I-2 suggested that they were similarly affected. Individual II-3 has a small head, a unilateral small thumb, and history of a tracheoesophageal fistula.

Figure 4 presents a Poznanski metacarpophalangeal profile analysis for II-1, III-2, and III-3.

\section{DISCUSSION}

We have described a family with autosomal dominant microcephaly with normal intelligence and vari- able digital anomalies. Affected individuals have microcephaly ( $<3$ rd centile) and short palpebral fissures. No evidence for craniosynostosis could be found on skull films of two affected individuals (III-2 and III-3). Two relatives required speech therapy but there is no evidence for learning disability or mental impairment. Only one relative had microcephaly and short palpebral fissures without hand or foot anomalies (III-4). Thumb hypoplasia was unilateral, bilateral, or absent. When present, the phalanges and the first metacarpal were affected and there was often limitation of flexion of the distal interphalangeal joints. These individuals had asymmetric shortening of the first metacarpal and a distinctive thinning of the proximal first metacarpal. Clinodactyly of the second and fifth fingers was common and is due to hypoplasia of the second phalanx of these digits. A concomitant reduction in the number of creases of these digits also was observed. The feet were often short $(<3$ rd centile) especially relative to height (often between the 25th and 50th centile) and there was variable syndactyly between toes or fingers. Some affected relatives had a gap between the first and second toes and a broad great toe.

There are numerous disorders combining microcephaly and digital anomalies. Many can be excluded on the basis of an autosomal recessive or X-linked inheritance and/or distinguishing findings [Hunter, 1993; McKusick, 1996; Opitz and Holt, 1990]. Since microcephaly was the consistent anomaly in affected relatives, a review of the literature with these key words generated a short list of potentially related syndromes. Autosomal dominant microcephaly syndromes were discussed briefly by Winter [1993]. Reports by Feingold [1975, 1978], Brunner and Winter [1991], and König et al. [1990] described collectively a syndrome of tracheoesophageal fistula, duodenal atresia, hypoplastic thumbs, brachymesophalangy, 4/5 syndactyly of the

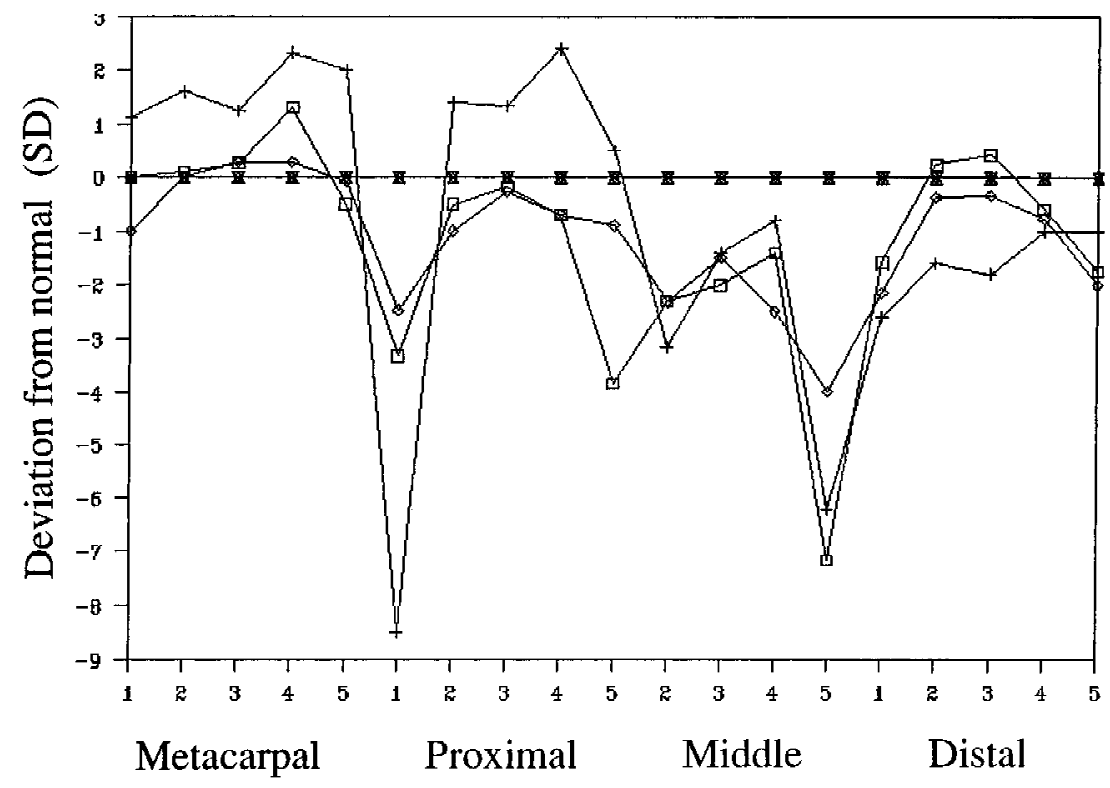

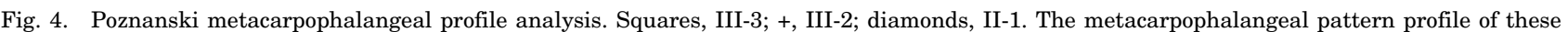

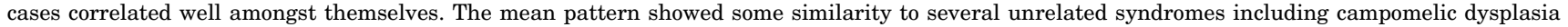
$(r=0.84)$, fibrodysplasia ossificans progressiva $(r=0.72)$, and hand-foot-genital $(r=0.70)($ data not shown). 
toes, and short palpebral fissures with microcephaly that appears to be similar to the family described here.

The similarities between the cases in the literature and those reported here make it likely that the differences observed probably represent the spectrum of this syndrome. While most patients in the literature have normal early development, it is important to point out that in family 1 of Brunner and Winter [1991], 5/7 persons attended special schools for learning problems or disabilities. No formal testing was performed to determine the individual learning difficulties necessitating this type of environment. In addition, no thumb hypoplasia was present in any relative, the degree of microcephaly was not as severe as reported here, and there was marked syndactyly of toes $4 / 5$ in $12 / 13$ relatives in that report. Whereas the hallmark of the families described by Brunner and Winter were clinodactyly of the fifth fingers and 4/5 toe syndactyly, the digital anomalies were the most variable in our patients. Moreover, microcephaly, clearly much less than the 3rd centile, was always present in our patients, whereas at least two affected persons in family 1 were at the 10 th centile for OFC.

The mean pattern profile for our family showed similarity to the mean pattern of the two hands published by König et al. [1990] $(\mathrm{r}=0.68)$ and to that of the girl in Feingold's report $[1975,1978](\mathrm{r}=0.91)$, which was calculated from the radiograph of the patient (which was kindly sent to us by the author). In addition, the thinning of the proximal portion of the first metacarpal seen in most of our family members was also evident on the radiograph we received from Dr. Feingold. However, it was not evident in the radiograph published by König et al [1990] and was in some of our cases milder on one side than the other. This may be a useful sign as it is not seen in many syndromes with first metacarpal hypoplasia.

Approximately $30 \%$ of the relatives reported by Brunner and Winter [1991] and the boy reported by Feingold [1978] had tracheoesophageal fistula and/or duodenal atresia. In two patients, this was associated with polyhydramnios. Polyhydramnios or duodenal atresia was not part of the history of any of the patients we examined. One individual, II-3, has a history of tracheoesophageal fistula. If the family described here is taken together with previous reports, the risk for TEF and/or duodenal atresia is $8 / 29$ or approximately $28 \%$.

The summary of Brunner and Winter [1991] listed 21 patients affected with the disorder, of which 9 were male and 12 were female. The family we describe consists of three males and three females known to be affected, and two other males likely to be (shaded in Fig. 1). The data support autosomal dominant inheritance with equal numbers of affected males and females. The occurrence of four miscarriages in one branch of the family reported here does not appear related to the inheritance of the mutation, since no miscarriages were reported for II-2 or the spouse of II-3.

All karyotypes of reported patients were normal. In some, attention was directed to $13 q$ due to the similar occurrence of hypoplastic thumbs, syndactyly of toes $4 / 5$, clinodactyly of the fifth fingers, microcephaly, and short palpebral fissures (among other problems) in patients with deletions of chromosome 13q22-qter [Schinzel, 1984]. That search failed to show evidence for deletion or rearrangement. Similarly, we found no detectable deletion. Efforts to determine the genetic defect responsible for this syndrome might begin by determining whether the mutation is linked to selected chromosome $13 q$ markers.

\section{ACKNOWLEDGMENTS}

We thank Dr. Lawrence Kuhns for assistance in obtaining the metacarpophalangeal profile analysis, Judy Worley for secretarial assistance, and Dr. Jerome L. Gorski for referring the family to the Pediatric Genetics Clinic. This paper is dedicated to Dr. James Asher, Jr. who died May 13, 1996.

\section{REFERENCES}

Brunner HG, Winter RM (1991): Autosomal dominant inheritance of abnormalities of the hands and feet with short palpebral fissures, variable microcephaly with learning disability, and oesophageal/duodenal atresia. J Med Genet 28:389-394.

Feingold M (1975): Case report 30. Synd Ident 3:16-17.

Feingold M (1978): An unusual microcephaly. Hosp Prac 13:44-49.

Hall JG, Froster-Iskenius UG, Allanson JE (1989): "Handbook of Normal Physical Measurements". Oxford, New York: Oxford University Press, pp 85-86, 139-144, 150, 240.

Hunter A (1993): Brain. In Stevenson RE, Hall JG, Goodman RM (eds): "Human Malformations and Related Anomalies." New York: Oxford University Press, pp 1-19.

König R, Selyer G, Stolp A, Fuchs S (1990): Microcephaly, mesobrachyphalangy and tracheoesophageal fistula: MMT syndrome. Dysmorphol Clin Genet 4:83-86.

McKusick V (1996): "Mendelian Inheritance in Man,” 11th ED. Baltimore: The Johns Hopkins University Press.

Schinzel A (1984): "Catalogue of Unbalanced Chromosome Aberrations in Man”. New York: Walter de Gruyter, pp 484-489.

Opitz JM, Holt MC (1990): Microcephaly: General considerations and aids to nosology. J Craniofac Genet Dev Biol 10:175-204.

Winter RM (1993): Distinctive autosomal or X-linked dominant syndrome of microcephaly, mild developmental delay, short stature, and distinctive face. Am J Med Genet 47:917-920. 